\title{
Younger age is an independent predictor of worse prognosis among Lebanese nonmetastatic breast cancer patients: analysis of a prospective cohort
}

\author{
This article was published in the following Dove Press journal: \\ Breast Cancer - Targets and Therapy \\ 10 June 2017 \\ Number of times this article has been viewed
}

\author{
Alissar El Chediak' \\ Raafat S Alameddine' \\ Ayman Hakim' \\ Lara Hilal ${ }^{2}$ \\ Sarah Abdel Massih' \\ Lana Hamieh ${ }^{3}$ \\ Deborah Mukherji' \\ Sally Temraz' \\ Maya Charafeddine' \\ Ali Shamseddine'
}

'Division of Hematology/Oncology, Department of Internal Medicine, 2Department of Radiation Oncology,

American University of Beirut Medical Center, Beirut, Lebanon; ${ }^{3}$ Division of Pulmonary and Critical Care Medicine, Brigham and Women's Hospital, Boston, MA, USA
Correspondence: Ali Shamseddine Division of Hematology/Oncology, Department of Internal Medicine, American University of Beirut Medical Center, PO Box II-0236, Riad El Solh, II 0 72020, Beirut, Lebanon

Tel +96I I 374374 extension 5390

Fax +96| I $3708 \mid 4$

Email as04@aub.edu.lb

\begin{abstract}
Background: Several retrospective studies have reported that younger age at presentation is associated with a worse prognosis for nonmetastatic breast cancer patients. In this study, we prospectively assessed the association between different baseline characteristics (age, tumor characteristics, mode of treatment, etc) and outcomes among newly diagnosed nonmetastatic Lebanese breast cancer patients.

Methods: We recruited a sample of 123 women newly diagnosed with nonmetastatic breast cancer presenting to American University of Beirut Medical Center. Immunohistochemical, molecular (vitamin D receptor, methylene tetrahydrofolate reductase polymorphisms), and genetic assays were performed. Patient characteristics were compared by age group $(<40$ and $\geq 40$ years). A Cox regression analysis was performed to evaluate the variables affecting the disease-free survival (DFS). Outcome data were obtained, and DFS was estimated.

Results: Among the 123 patients, 47 were 40 years of age or younger, and 76 were older than 40 years. Median follow-up duration was 58 months. Nine out of 47 patients $<40$ years $(19.1 \%)$ experienced disease relapse in contrast to four out of 76 patients $>40$ years $(5.2 \%)$. A wide immunohistochemical panel included Ki-67, cyclin B1, p53, platelet-derived growth factor receptor, and vascular endothelial growth factor receptor, and did not reveal any significant difference in these markers between the two age groups. Older patients had a larger percentage of Luminal A than younger patients. On multivariate analysis including age, stage, grade, and subtype, only age $<40$ and stage were significantly associated with shorter DFS with hazard ratios of 4 ( $p=0.03,95 \%$ confidence interval [CI]: $1.1-13.5)$ and 3 ( $p=0.03,95 \% \mathrm{CI}: 0.8-14.9)$, respectively. The estimated 5-year DFS for patients $>40$ years was $90 \%$, and for patients $<40$ years was $37 \%$.
\end{abstract}

Conclusion: Being $<40$ years old was an independent risk factor for recurrence in this cohort of patients.

Keywords: young, subtypes, disease-free survival, worse prognosis, early, risk factor

\section{Introduction}

Breast cancer is the most common type of cancer in women in the US especially affecting those in their fifth and sixth decades. ${ }^{1}$ In the Arab World, it represents one-third of cancers among women, with a constantly rising incidence. ${ }^{2}$ In Lebanon, $\sim 69$ out of 100,000 women are diagnosed with breast cancer per year. ${ }^{2}$ Of all the Lebanese women with breast cancer, $18 \%-20 \%$ present at an age younger than 40 . This high incidence is in sharp contrast with Europe and US where only 5\%-7\% of breast cancer patients are younger than $40 .^{3,4}$ Breast cancer in young women has a distinct biological behavior 
than in older women. It is more aggressive and foreshadows a worse prognosis. ${ }^{5}$

The role of age as a diagnostic factor is controversial as several studies have presented discordant results. Abulkhair et al found that among Saudi patients with triple-negative breast cancer, age $<40$ years was a significant independent marker of worse overall survival. ${ }^{6}$ In another study by Anders et al, among women with early-stage breast cancer, younger patients were found to have larger tumors of higher grade, more lymph node positivity, lower estrogen receptor expression and higher HER2/neu overexpression, and eventually worse disease-free survival (DFS). ${ }^{7}$ In a Chinese study, invasive breast cancer in younger patients was associated with more aggressive pathological features, such as a higher percentage of grade 3 histology, a higher proportion of tumors with lymphovascular invasion, and a more multifocal disease. ${ }^{8}$ On the other hand, a study conducted in Switzerland involving 2997 breast cancer patients assessed the impact of age at diagnosis on clinical presentation and other variables. It was found that age is not an independent prognostic factor when accounting for breast tumor characteristics and treatment. ${ }^{9}$

Colleoni et al evaluated the biological features and stage at presentation of 1427 patients with breast cancer. ${ }^{5}$ They found that the pathological tumor size, nodal status, and number of positive axillary lymph nodes have a similar distribution among the younger and the older cohorts, thus not supporting the previous data indicating more advanced operable disease in younger patients at diagnosis. ${ }^{5}$

In order to better delineate the impact of age on outcomes in Lebanese breast cancer patients, we conducted a prospective study on Lebanese women newly diagnosed with breast cancer. We assessed the association between different pathological, molecular, and genetic markers and outcomes, and their interaction with age.

\section{Methods}

\section{Study design and patient recruitment}

This was a pilot prospective study conducted at the American University of Beirut Medical Center (AUBMC), a large tertiary referral center in Lebanon. It included newly diagnosed women with histologically confirmed nonmetastatic breast carcinoma over the period from July 2011 till May 2014. Our patient population did not include patients with in situ cancer, inflammatory cancer, bilateral cancer, distant metastases, or a history of previous cancer. Patients were divided into two age groups according to a cutoff age of 40 years. Patients were recruited from private oncology clinics and inpatient wards at AUBMC and provided written informed consent to participate. Data regarding patient's demographics, risk factors, and past medical history were collected using a questionnaire form. In addition, clinical and hospital charts were reviewed in order to complete the medical information. The study protocol was approved by the Institution Review Board of the American University of Beirut.

\section{Immunohistochemistry}

A hematoxylin- and eosin-stained tumor section was examined, and the tumor was graded according to the modified Bloom-Richardson-Elston grading system. ${ }^{10}$ Additional parameters such as the concomitant presence of carcinoma in situ and lymphovascular invasion were also evaluated and recorded. Immunohistochemical stains for estrogen receptor, progesterone receptor, HER2/neu, p53, vascular endothelial growth factor receptor (VEGFR), cyclin B1, and Ki-67 were also performed. Interpretation of the immunohistochemical stains was performed according to a grading system that accounts for both the intensity of staining (weak, moderate, strong) and the number of positive cells $(<5 \%, 5-50 \%$, $>50 \%)^{11}$

\section{Molecular analysis}

DNA was extracted from whole blood samples. DNA amplification was performed by reverse transcription polymerase chain reaction to test for vitamin $\mathrm{D}$ receptor $(V D R)$ singlenucleotide polymorphisms and methylene tetrahydrofolate reductase (MTHFR) single-nucleotide polymorphisms. Specific primer restriction enzymes were used, and the resulting fragments corresponding to specific genotypes were examined.

\section{Genetic analysis}

DNA was extracted from the stored blood samples. Analysis of BRCA 1 and BRCA 2 genes was done using the Sanger technique.

\section{Statistical analysis}

The analysis included descriptive analysis and compared the two groups (age $\geq 40$ and age $<40$ ) for tumor characteristics, pathological variables, molecular variables, treatment, and outcome using the Pearson chi-square. Fisher's exact test was also used to account for the low number of patients $<40$ years old. Mean size of the tumor was compared between the two groups using Student's $t$-test. DFS was calculated from the diagnosis date to relapse or the end of follow-up in case no recurrence was documented (censored observations). DFS 
curves were plotted using the Kaplan-Meier curves; the log rank was used to check for significant difference in DFS between the two studied groups. A Cox regression analysis was used to evaluate the variables affecting the DFS time using conditional backward stepwise method. The final step in the regression retained the most significant variables to the model controlling for all other variables. The hazard ration and its $95 \%$ confidence interval were evaluated for each variable. The statistical significance was considered at $p<0.05$. All analyses were done using SPSS Version 23.0.

\section{Variable definitions}

Patients were classified into groups according to molecular subtypes as defined by St. Gallen's consensus (2011): ${ }^{12}$

1. Luminal A: ER positive and/or PR positive, HER2 negative, and $\mathrm{Ki}-67<14 \%$ or low/intermediate grade

2. Luminal B (combined as one subtype)

- Luminal B (HER2 negative): ER and/or PR positive, HER2 negative, and Ki-67 $>14 \%$ or high grade

- Luminal B (HER2 positive): ER and/or PR positive, any $\mathrm{Ki}-67$, and HER2 overexpressed or amplified

3. Erb-B2 overexpression: ER negative, PR negative, and HER2 positive

4. Triple negative: ER negative, PR negative, and HER2 negative

\section{Results}

A total of 123 patients were recruited, of which 47 (38\%) were younger than 40 years and $76(62 \%)$ were 40 years of age or older (Table 1). The median age of the patients in the sample was 44 years. Of all patients, $78 \%$ presented with stage I or II breast cancer (Table 1). Sixty-three percent of patients $>40$ and $33 \%$ of patients $<40$ presented with stage I or II disease. Intralobular carcinoma was found in $9.1 \%$ of patients; it was more common in the younger age group $(15.2 \%)$ than the older group (5.3\%). The older age group had a higher incidence of concurrent lobular and intraductal carcinoma ( $4 \%$ vs. $2.2 \%$ ). In terms of molecular subtypes, Luminal A was the most common subtype in both the age groups. As for the mode of treatment, the proportion of young patients treated with herceptin was more than older patients (Table 2); however, the result was not statistically significant.

Median follow-up duration was 58 months. The estimated 5 -year DFS for patients $>40$ was $90 \%$, and for patients $<40$ was $37 \%$ (Figure 1). Cox regression assessing variables influencing the time to disease showed that stage and age were the two variables that fitted the model controlling for grade, and molecular subtype, which were not found significant for the model. Younger patients had fourfold the chance of recurrence compared to the older group. On multivariate analysis with age as a continuous variable, there was a significant $9 \%$ increase in risk of recurrence for every 1 year younger $(p=0.027)$.

\section{Discussion}

Several research studies across the globe have investigated the histopathological characteristics of breast cancer in younger and older women, and the prognostic role of age, and have reported conflicting results. ${ }^{9,13,14}$ In accordance with several prior reports, this study found that women who presented with breast cancer at an early age had a shorter DFS..$^{6-8,13,15}$ On the other hand, some studies, such as the one conducted by Rapiti et al, have reported that age is not an independent prognostic factor when accounting for breast tumor characteristics and treatment. However, young patients constituted only $3 \%$ of the sample, and hence, their study was of low statistical power. ${ }^{9}$

Worse outcomes in the young population were attributed to specific prognostic pathological features such as a higher grade of differentiation, more advanced stage at presentation, higher HER2 expression, and higher rates of axillary lymph node involvement. ${ }^{3,16,17}$ This study also looked at the histological type, lymphovascular invasion, hormone receptors, Ki-67, p53, cyclin B1, VEGFR, MTHFR polymorphisms, and $V D R$ polymorphism. Stage, histological type, grade, lymph node involvement, lymphovascular invasion, hormone receptors, HER2/neu receptors, Ki-67, p53, cyclin B1, VEGFR, $M T H F R$ polymorphisms, and $V D R$ polymorphism were not found to be statistically different between the two age groups (Tables 3 and 4). Nonetheless, multivariate analysis for DFS revealed that the stage $(p=0.033)$ and age $(p=0.03)$ were independent prognostic factors. Age was kept in the model of Cox regression as per conditional backward stepwise method indicating that it is an important factor in the model that impacts the results.

These findings are also commensurate with the results published in a Turkish study where stage IIIA breast cancer was seen more frequently in young patients. ${ }^{17}$ Moreover, the pathology and cancer registry records of 101 patients in Mount Sinai Medical Center were reviewed. ${ }^{18}$ They found that patients younger than 36 years were more likely to be diagnosed with stage II or III cancer (60\% vs. $43 \%$, overall $p<0.001) .{ }^{18}$ As for the size of the tumors in younger women, they were about the same size as that of older patients (Table 1). However, this result was not significant. Thus, the 
Table I Comparison of tumor characteristics between age groups

\begin{tabular}{|c|c|c|c|c|c|c|}
\hline Variable & Value & $\begin{array}{l}\text { Total } \\
\text { patients }(N=123)\end{array}$ & $\begin{array}{l}\text { Patients } \\
<40 \text { years } \\
(\mathrm{N}=47)\end{array}$ & $\begin{array}{l}\text { Patients } \\
>40 \text { years } \\
(\mathrm{N}=76)\end{array}$ & $p$-value & $\begin{array}{l}\text { Missing } \\
\text { data }\end{array}$ \\
\hline \multirow[t]{4}{*}{$T$} & I & $43.9 \%(54)$ & $38.3 \%(18)$ & $47.4 \%(36)$ & $0.019 *$ & 0 \\
\hline & 2 & $43.9 \%(54)$ & $40.4 \%$ (19) & $46.1 \%(35)$ & & \\
\hline & 3 & $8.9 \%(I I)$ & $19.1 \%(9)$ & $2.6 \%(2)$ & & \\
\hline & 4 & $3.3 \%(4)$ & $2.1 \%(I)$ & $3.9 \%(3)$ & & \\
\hline \multirow[t]{4}{*}{$\mathrm{N}$} & 0 & $53.3 \%(65)$ & $45.7 \%(2 I)$ & $57.9 \%(44)$ & 0.631 & I \\
\hline & I & $32.8 \%(40)$ & $39.1 \%(18)$ & $28.9 \%(22)$ & & \\
\hline & 2 & $9.8 \%(12)$ & $10.9 \%(5)$ & $9.2 \%(7)$ & & \\
\hline & 3 & $4.1 \%(5)$ & $4.3 \%(2)$ & $3.9 \%(3)$ & & \\
\hline \multirow[t]{3}{*}{ Stage } & 1 & $32.5 \%(40)$ & $23.4(\mathrm{II})$ & $38.2 \%(29)$ & 0.141 & 0 \\
\hline & II & $45.5 \%(56)$ & $46.8 \%(22)$ & $44.7 \%(34)$ & & \\
\hline & III & $22 \%(27)$ & $29.8 \%(14)$ & $17.1 \%(13)$ & & \\
\hline \multirow[t]{3}{*}{ Grade } & I & $\mid 7.2 \%(2 \mid)$ & $15.2 \%(7)$ & $18.4 \%(35)$ & 0.801 & I \\
\hline & 2 & $45.1 \%(55)$ & $43.5 \%(20)$ & $46.1 \%(35)$ & & \\
\hline & 3 & $37.7 \%(46)$ & $41.3 \%(19)$ & $35.5 \%(27)$ & & \\
\hline \multirow[t]{3}{*}{ Type } & IDC & $87.6 \%(106)$ & $82.6 \%(38)$ & $90.7 \%(68)$ & 0.182 & 2 \\
\hline & ILC & $9.1 \%(I I)$ & $15.2 \%(7)$ & $5.3 \%(4)$ & & \\
\hline & IDC and ILC & & $2.2 \%(I)$ & $4 \%(3)$ & & \\
\hline Tumor size (mean), cm & & & 2.6 & 2.7 & 0.8 & \\
\hline \multirow[t]{2}{*}{ LVI } & No & $62.1 \%(72)$ & $53.5 \%(23)$ & $67.1 \%(49)$ & 0.168 & 7 \\
\hline & Yes & $37.9 \%(44)$ & $46.5 \%(20)$ & $32.9 \%(24)$ & & \\
\hline \multirow[t]{4}{*}{ ER } & Negative & $18 \%(22)$ & $21.3 \%(10)$ & $16 \%(12)$ & 0.210 & I \\
\hline & Weakly positive & $7.4 \%(9)$ & $12.8 \%(6)$ & $4 \%(3)$ & & \\
\hline & Moderately positive & $35.2 \%(43)$ & $34 \%(16)$ & $36 \%(27)$ & & \\
\hline & Strongly positive & $39.3 \%(48)$ & $31.9 \%(15)$ & $44 \%(33)$ & & \\
\hline \multirow[t]{4}{*}{ PR } & Negative & $27 \%(33)$ & $31.9 \%(15)$ & $24 \%(18)$ & 0.310 & I \\
\hline & Weakly positive & $13.9 \%(17)$ & $19.1 \%(9)$ & $10.7 \%(8)$ & & \\
\hline & Moderately positive & $29.5 \%(36)$ & $23.4 \%(11)$ & $33.3 \%(25)$ & & \\
\hline & Strongly positive & $29.5 \%(36)$ & $25.5 \%(12)$ & $32 \%(24)$ & & \\
\hline \multirow[t]{2}{*}{ HER2 } & Negative & $74.6 \%(91)$ & $26 \%(33)$ & $47 \%(58)$ & 0.4 & I \\
\hline & Positive & $25.4 \%(31)$ & $11.4 \%(14)$ & $14 \%(17)$ & & \\
\hline \multirow[t]{4}{*}{ Subtype } & Luminal $\mathrm{A}$ & $41 \%(50)$ & $38.3 \%(18)$ & $42.7 \%(32)$ & 0.565 & I \\
\hline & Luminal B & $32 \%(39)$ & $27.7 \%(13)$ & $34.7 \%(26)$ & & \\
\hline & Triple negative & $19.7 \%(24)$ & $25.5 \%(12)$ & $16 \%(12)$ & & \\
\hline & Erb-B2 & $7.4 \%(9)$ & $8.5 \%(4)$ & $6.7 \%(5)$ & & \\
\hline
\end{tabular}

Note: *Fisher's exact test was used for cells containing $<5 \%$ data.

Abbreviations: IDC, intraductal carcinoma; ILC, intralobular carcinoma; LVI, lymphovascular invasion; ER, estrogen receptor; PR, progesterone receptor.

Table 2 Comparison of treatment

\begin{tabular}{|c|c|c|c|c|c|c|}
\hline Variable & Value & $\begin{array}{l}\text { Total } \\
\text { patients } \\
(\mathrm{N}=\mid 23)\end{array}$ & $\begin{array}{l}\text { Patients } \\
<40 \text { years } \\
(\mathrm{N}=47)\end{array}$ & $\begin{array}{l}\text { Patients } \\
>40 \text { years } \\
(\mathrm{N}=76)\end{array}$ & $p$-value & $\begin{array}{l}\text { Missing } \\
\text { data }\end{array}$ \\
\hline Neo-adjuvant & No & $75.2 \%(91)$ & $65.2 \%(30)$ & $81.3 \%(6 I)$ & 0.05 & 2 \\
\hline chemotherapy & Yes & $24.8 \%(30)$ & $34.8 \%(16)$ & $18.7 \%(14)$ & & \\
\hline \multirow[t]{3}{*}{ Surgery } & No surgery & $0.8 \%(I)$ & $2.2 \%(\mathrm{I})$ & $0.0 \%(0)$ & $0.059^{*}$ & I \\
\hline & Mastectomy & $45.1 \%(55)$ & $54.3 \%(25)$ & $39.5 \%(30)$ & & \\
\hline & Lumpectomy & $54.1 \%(66)$ & $43.5 \%(20)$ & $60.5 \%(46)$ & & \\
\hline Adjuvant & No & $36.4 \%(43)$ & $29.5 \%(13)$ & $40.5 \%(30)$ & 0.244 & 5 \\
\hline chemotherapy & Yes & $63.6 \%(75)$ & $70.5 \%(3 I)$ & $59.5 \%(44)$ & & \\
\hline \multirow[t]{2}{*}{ Herceptin use } & No & $76.0 \%(92)$ & $67.4 \%(29)$ & $80.8 \%(63)$ & 0.1 & 5 \\
\hline & Yes & $24.0 \%(29)$ & $32.6 \%(14)$ & $19.2 \%(15)$ & & \\
\hline \multirow[t]{2}{*}{ Hormone therapy } & No & $17.6 \%(21)$ & $19.6 \%(9)$ & $16.4 \%(12)$ & 0.806 & 4 \\
\hline & Yes & $82.4 \%(98)$ & $80.4 \%(37)$ & $83.6 \%(6 I)$ & & \\
\hline \multirow[t]{2}{*}{ Radiation therapy } & No & $18.9 \%(2 \mid)$ & $19.5 \%(8)$ & $18.6 \%(13)$ & I & 12 \\
\hline & Yes & $81.1 \%(90)$ & $80.5 \%(33)$ & $81.4 \%(57)$ & & \\
\hline
\end{tabular}

Note: *Fisher's exact test was used for cells containing $<5 \%$ data. 
hypothesis that younger patients have larger tumors still holds and is supported in other studies. ${ }^{19}$

The prevalence of $B R C A$ mutations amongst breast cancer patients is of importance as they are considered to be strong predictors of breast cancer. BRCA 1 and BRCA 2 mutations were mostly absent in the sample of this study. Moreover, the distribution was not significantly different between the two age groups (Table 4). These results are similar to another leading Lebanese study by El Saghir et al where few patients had the mutations. ${ }^{20}$ Thus, the prevalence

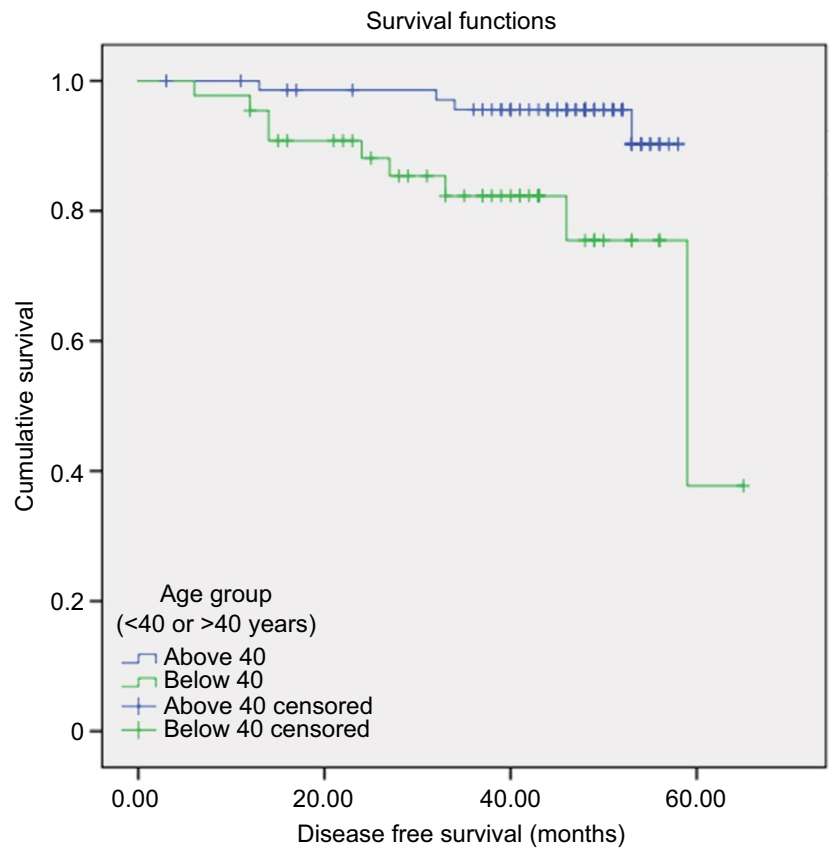

Figure I Disease-free survival functions. of deleterious $B R C A$ mutations is lower than expected and does not support the hypothesis that $B R C A$ mutations alone cause the observed high percentage of breast cancer in young women of Lebanese descent. ${ }^{20}$ We therefore recommend further studies to investigate the prognostic implications of other genetic mutations and pathological markers such as PDGFR- $\beta$, PDGFR- $\alpha$, fibroblast growth factors, and NGN-2 in addition to microRNAs across different age groups.

Different DFS rates have been reported in the literature, although not a lot of studies correlated age with these survival rates. In this study, a DFS of 53 months is reported for those $<40$ years of age. An Egyptian retrospective study of 379 young breast cancer patients aged $<35$ years conducted by Farouk et al reported a DFS of 50 months. ${ }^{21}$ Another study in China analyzed 132 patients with operable breast cancer who were younger than 35 years. They described a median local recurrence-free survival of 87 months. ${ }^{22}$ On the other hand, a study in Geneva by Rapiti et al showed that the 5-year DFS was not different between the very young ( $<35$ years), the young (36-49 years), and the older (50-69 years) women. ${ }^{9}$ Some of these results can be explained by same ethnic origins of populations in Asia as opposed to those in Europe.

The availability of the hormone receptor and Ki-67 index information in the patients studied here allowed us to separate breast cancer subtypes. Distinct molecular subtypes of breast cancer are associated with different risks of early disease recurrence, response to therapy, and overall survival. ${ }^{23-25}$ The classification into different subtypes allowed the development of treatments for breast cancer that have improved the prognosis for particular subgroups of patients. ${ }^{15}$ Few studies

Table 3 Comparison of immunohistochemical characteristics between age groups

\begin{tabular}{|c|c|c|c|c|c|c|}
\hline Variable & Value & $\begin{array}{l}\text { Total } \\
\text { patients } \\
(\mathrm{N}=\mid 26)\end{array}$ & $\begin{array}{l}\text { Patients } \\
<40 \text { years } \\
(N=46)\end{array}$ & $\begin{array}{l}\text { Patients } \\
>40 \text { years } \\
(\mathrm{N}=80)\end{array}$ & $p$-value & $\begin{array}{l}\text { Missing } \\
\text { data }\end{array}$ \\
\hline \multirow[t]{5}{*}{ Cyclin BI } & Negative & $45.7 \%(46)$ & $45.7 \%(16)$ & $44.8 \%(30)$ & $0.919 *$ & 21 \\
\hline & Weakly positive & $22.5 \%(23)$ & $25.7 \%(9)$ & $20.9 \%(14)$ & & \\
\hline & Moderately positive & $22.5 \%(23)$ & $20.7 \%(7)$ & $23.9 \%(16)$ & & \\
\hline & Strongly positive & $7.8 \%(8)$ & $8.6 \%(3)$ & $7.5 \%(3)$ & & \\
\hline & Focal & $2.0 \%(2)$ & $0.0 \%(0)$ & $3.0 \%(2)$ & & \\
\hline \multirow[t]{4}{*}{ P53 } & Negative & $46.1 \%(47)$ & $42.9 \%(15)$ & $47.8 \%(32)$ & 0.683 & 21 \\
\hline & Weakly positive & $22.5 \%(23)$ & $22.9 \%(8)$ & $22.4 \%(15)$ & & \\
\hline & Moderately positive & $11.8 \%(12)$ & $17.1 \%(6)$ & $9.0 \%(6)$ & & \\
\hline & Strongly positive & $19.6 \%(20)$ & $17.1 \%(6)$ & $20.9 \%(14)$ & & \\
\hline \multirow[t]{3}{*}{ VEGFR } & Negative & $60.8 \%(62)$ & $70.6 \%(24)$ & $55.9 \%(38)$ & 0.31 & 24 \\
\hline & Weakly positive & $30.4 \%(31)$ & $20.6 \%(7)$ & $35.3 \%(24)$ & & \\
\hline & Moderately positive & $8.8 \%(9)$ & $8.8 \%(3)$ & $8.8 \%(6)$ & & \\
\hline \multirow[t]{3}{*}{ Ki67 } & $<10 \%$ & $21.2 \%(22)$ & $25.6 \%(10)$ & $18.5 \%(12)$ & 0.263 & 19 \\
\hline & $10-20 \%$ & $27.9 \%(29)$ & $17.9 \%(7)$ & $33.8 \%(22)$ & & \\
\hline & $>20 \%$ & $51.0 \%(53)$ & $56.4 \%(22)$ & $47.7 \%(3 I)$ & & \\
\hline
\end{tabular}

Note: *Fisher's exact test was used for cells containing $<5 \%$ data.

Abbreviation: VEGFR, vascular endothelial growth factor receptor. 
Table 4 Comparison of genetic variations between age groups

\begin{tabular}{|c|c|c|c|c|c|c|}
\hline Variable & Value & $\begin{array}{l}\text { Total } \\
\text { patients } \\
(\mathrm{N}=126)\end{array}$ & $\begin{array}{l}\text { Patients } \\
<40 \text { years } \\
(\mathrm{N}=46)\end{array}$ & $\begin{array}{l}\text { Patients } \\
>40 \text { years } \\
(\mathrm{N}=80)\end{array}$ & $p$-value & $\begin{array}{l}\text { Missing } \\
\text { data }\end{array}$ \\
\hline \multirow[t]{3}{*}{ BRCA I } & Negative & $83 \%(104)$ & $92.1 \%(35)$ & $95.8 \%(69)$ & 0.5 & 16 \\
\hline & Positive & $2.4 \%(3)$ & $2.6 \%(I)$ & $2.8 \%(2)$ & & \\
\hline & Variant & $2.4 \%(3)$ & $2.8 \%(2)$ & $2.6 \%(I)$ & & \\
\hline \multirow[t]{3}{*}{ BRCA 2} & Negative & $76 \%(96)$ & $89.2 \%(33)$ & $91.3 \%$ (63) & & \\
\hline & Positive & $4 \%(5)$ & $5.4 \%(2)$ & $4.3 \%(3)$ & & \\
\hline & Variant & $4 \%(5)$ & $5.4 \%(2)$ & $4.3 \%(3)$ & & \\
\hline \multirow[t]{3}{*}{ MTHFR677 } & $\mathrm{CC}$ & $36.0 \%(4 I)$ & $37.5 \%(15)$ & $35.1 \%(26)$ & 0.814 & 9 \\
\hline & $\mathrm{CT}$ & $45.6 \%(52)$ & $47.5 \%(19)$ & $44.6 \%(33)$ & & \\
\hline & $\mathrm{TT}$ & $18.4 \%(2 \mid)$ & $15.0 \%(6)$ & $20.3 \%(15)$ & & \\
\hline \multirow[t]{3}{*}{ MTHFRI 298} & AA & $49.1 \%(56)$ & $50.0 \%(20)$ & $48.6 \%(36)$ & $0.629 *$ & 9 \\
\hline & $A C$ & $44.7 \%(5 I)$ & $47.5 \%(19)$ & $43.2 \%(32)$ & & \\
\hline & $\mathrm{CC}$ & $6.1 \%(7)$ & $2.5 \%(\mathrm{I})$ & $8.1 \%(8)$ & & \\
\hline \multirow[t]{3}{*}{ VDR-Apal } & AA & $34.2 \%$ (39) & $42.5 \%(I 7)$ & $29.7 \%(22)$ & 0.390 & 9 \\
\hline & $\mathrm{Aa}$ & $47.4 \%(54)$ & $42.5 \%(17)$ & $50.0 \%(37)$ & & \\
\hline & aa & $18.4 \%(21)$ & $15.0 \%(6)$ & $20.3 \%(15)$ & & \\
\hline \multirow[t]{3}{*}{ VDR-Taql } & $\mathrm{TT}$ & $47.4 \%(54)$ & $45.0 \%(18)$ & $48.6 \%(46)$ & $0.762^{*}$ & 9 \\
\hline & $\mathrm{Tt}$ & $40.4 \%(46)$ & $45.0 \%(18)$ & $37.8 \%(28)$ & & \\
\hline & $\mathrm{tt}$ & $12.3 \%(14)$ & $10.0 \%(4)$ & $13.5 \%(10)$ & & \\
\hline \multirow[t]{3}{*}{ VDR-Bsml } & BB & $14.9 \%(17)$ & $10.0 \%(4)$ & $17.6 \%(13)$ & $0.162 *$ & 9 \\
\hline & $\mathrm{Bb}$ & $43.0 \%$ (49) & $55.0 \%(22)$ & $36.5 \%(27)$ & & \\
\hline & $\mathrm{bb}$ & $42.1 \%(48)$ & $35.0 \%(14)$ & $45.9 \%(34)$ & & \\
\hline
\end{tabular}

Note: *Fisher's exact test was used for cells containing $<5 \%$ data.

Abbreviations: MTHFR, methylene tetrahydrofolate reductase; VDR, vitamin D receptor.

Table 5 Subtypes across the two age groups

\begin{tabular}{lllllll}
\hline Age group & Total & Luminal A & Luminal B & Triple negative & Erb-B2 & p-value \\
\hline$<40$ years & $39.1 \%(47)$ & $38.3 \%(18)$ & $27.7 \%(13)$ & $25.5 \%(12)$ & $8.5 \%(4)$ & 0.036 \\
$>40$ years & $60.9 \%(75)$ & $42.7 \%(32)$ & $34.7 \%(26)$ & $16 \%(12)$ & $6.7 \%(5)$ & $<0.0001$ \\
Missing & 1 & & & & & \\
\hline
\end{tabular}

have suggested that the effect of age on outcome may vary by tumor subtype. ${ }^{15,26-28}$ As in other studies, ${ }^{24,29}$ Luminal A was the most common subtype in both the age groups (Table 5). However, older patients had a larger percentage of Luminal A subtype than younger patients. The results of this study are concordant with repeated observations that Luminal A tumors exhibit the best prognosis with respect to survival. ${ }^{24,30}$ This is a possible explanation of why patients $>40$ years had better outcomes and less recurrence rates.

DFS adjusted for all subtypes did not show a statistical significance between those aged $<40$ years and those aged $>40$ years. A recent study by Partridge et al assessed the relationship between age and breast cancer-specific survival. ${ }^{15}$ Their sample consisted of 17,575 women with stage I-III breast cancer, and 1,916 women were $<40$ years of age at diagnosis. ${ }^{15}$ They concluded that the effect of age on survival of women with early-stage breast cancer seems to vary by breast cancer subtype and that young age seems to be particularly prognostic in women with luminal breast cancers.
Their large sample size accounts for the difference between the results of their study and the present study.

Lebanese subjects were found to have lower levels of serum vitamin D despite adequate sunlight exposure. ${ }^{31}$ In the present cohort, the low mean level of serum vitamin D at presentation is commensurate with the prior report by Hoteit et al. ${ }^{31}$ The mean of vitamin D serum levels and the different $V D R$ polymorphisms was not different between the age groups. Vitamin D levels in the sample of patients ranged between 3.0 and $87.0 \mathrm{ng} / \mathrm{mL}$, with a median level of $13.9 \mathrm{ng} / \mathrm{mL}$. There was no significant difference in the mean vitamin D levels between the two groups (19.6 and 18.8 for the $>40$ and $<40$ groups, respectively; $p=0.82$ ). There was also no statistical difference between the three $V D R$ polymorphisms among the old and young breast cancer patients. This is in concurrence with a study by Arabi et al which showed that in the Lebanese population there was no difference in VDR polymorphisms between those $<40$ years of age and those $>40$ years of age. ${ }^{32}$ 
This study sheds light on features that can influence the prognosis of young nonmetastatic breast cancer patients. Nonetheless, some other prognostic factors like extra-nodal extension of nodal metastasis should be examined. It was found that extra-nodal extension of nodal metastasis in sentinel lymph node-positive breast cancer seems to be associated with a poorer prognosis. ${ }^{33}$ Another study should be conducted to assess extra-nodal extension of nodal metastasis in young breast cancer patients and compare it to the older patients.

\section{Conclusion}

Although this study found in a cohort of Lebanese breast cancer patients that patients $<40$ years had worse DFS rates, there was no significant difference in the observed clinical, pathological, and molecular characteristics between those $<40$ years and those $>40$ years.

\section{Acknowledgment}

The abstract of this paper was presented at the 4th Annual Beirut Breast Cancer Conference: Advances in Breast Cancer Management and Updates held in Beirut, Lebanon, on February 11-13, 2016, as an abstract with interim findings. ${ }^{34}$

\section{Disclosure}

This work was supported by a grant to the American University of Beirut Medical Center from GlaxoSmithKline (GSK) (grant number 114579) for Ali Shamseddine. The authors report no other conflicts of interest in this work.

\section{References}

1. National Cancer Institute. SEER Cancer Statistics Factsheets: Female Breast Cancer. Bethesda, MD: National Cancer Institute; 2016.

2. Nagi S, El Saghir OA. Epidemiology, prevention and management guidelines for breast cancer in Arab countries. Pan Arab J Oncol. 2010;3: $12-18$.

3. Assi HA, Khoury KE, Dbouk H, Khalil LE, Mouhieddine TH, El Saghir NS. Epidemiology and prognosis of breast cancer in young women. J Thorac Dis. 2013;5 (Suppl 1):S2-S8.

4. Gnerlich JL, Deshpande AD, Jeffe DB, Sweet A, White N, Margenthaler JA. Elevated breast cancer mortality in women younger than age 40 years compared with older women is attributed to poorer survival in early-stage disease. J Am Coll Surg. 2009;208(3):341-347.

5. Colleoni M, Rotmensz N, Robertson C, et al. Very young women ( $<35$ years) with operable breast cancer: features of disease at presentation. Ann Oncol. 2002;13(2):273-279.

6. Abulkhair O, Moghraby JS, Badri M, Alkushi A. Clinicopathologic features and prognosis of triple-negative breast cancer in patients 40 years of age and younger in Saudi Arabia. Hematol Oncol Stem Cell Ther. 2012;5(2):101-106.

7. Anders CK, Hsu DS, Broadwater G, et al. Young age at diagnosis correlates with worse prognosis and defines a subset of breast cancers with shared patterns of gene expression. J Clin Oncol. 2008;26(20):3324-3330.

8. Yeo W, Lee HM, Chan A, et al. Risk factors and natural history of breast cancer in younger Chinese women. World J Clin Oncol. 2014;5(5): 1097-1106.
9. Rapiti E, Fioretta G, Verkooijen HM, et al. Survival of young and older breast cancer patients in Geneva from 1990 to 2001. Eur J Cancer. 2005;41(10):1446-1452.

10. Edge SB, Compton CC. The American Joint Committee on Cancer: the 7th edition of the AJCC cancer staging manual and the future of TNM. Ann Surg Oncol. 2010;17(6):1471-1474.

11. Bhargava V, Jain M, Agarwal K, Thomas S, Singh S. Critical appraisal of cytological nuclear grading in carcinoma of the breast and its correlation with ER/PR expression. J Cytol. 2008;25(2):58-61.

12. Goldhirsch A, Wood WC, Coates AS, Gelber RD, Thürlimann B, Senn HJ; Panel members. Strategies for subtypes - dealing with the diversity of breast cancer: highlights of the St Gallen International Expert Consensus on the Primary Therapy of Early Breast Cancer 2011. Ann Oncol. 2011;22:1736-1747.

13. El Saghir NS, Seoud M, Khalil MK, et al. Effects of young age at presentation on survival in breast cancer. BMC Cancer. 2006;6: 194.

14. Swanson GM, Lin CS. Survival patterns among younger women with breast cancer: the effects of age, race, stage, and treatment. J Natl Cancer Inst Monogr. 1994;(16):69-77.

15. Partridge AH, Hughes ME, Warner ET, et al. Subtype-dependent relationship between young age at diagnosis and breast cancer survival. J Clin Oncol. 2016;34(27):3308-3314.

16. Cvetanovic A, Popovic L, Filipovic S, et al. Young age and pathological features predict breast cancer outcome - report from a dual Institution experience in Serbia. J BUON. 2015;20(6):1407-1413.

17. Aksaz E, Atasoy G, Öncel T, et al. Profiles and predictive factors in young age breast cancer patients (retrospective study). J Breast Health. 2012;8(4):175-179.

18. Gajdos C, Tartter PI, Bleiweiss IJ, Bodian C, Brower ST. Stage 0 to stage III breast cancer in young women. J Am Coll Surg. 2000;190(5): 523-529.

19. Anders CK, Johnson R, Litton J, Phillips M, Bleyere A. Breast cancer before age 40 years. Semin Oncol. 2009;36(3):237-249.

20. El Saghir NS, Zgheib NK, Assi HA, et al. BRCA1 and BRCA2 mutations in ethnic Lebanese Arab women with high hereditary risk breast cancer. Oncologist. 2015;20(4):357-364.

21. Farouk O, Ebrahim MA, Senbel A, et al. Breast cancer characteristics in very young Egyptian women $</=35$ years. Breast Cancer (Dove Med Press). 2016;8:53-58.

22. Zhao Y, Dong X, Li R, Song J, Zhang D. Correlation between clinicalpathologic factors and long-term follow-up in young breast cancer patients. Transl Oncol. 2015;8(4):265-272.

23. Engstrom MJ, Opdahl S, Hagen AI, et al. Molecular subtypes, histopathological grade and survival in a historic cohort of breast cancer patients. Breast Cancer Res Treat. 2013;140(3):463-473.

24. Voduc KD, Cheang MC, Tyldesley S, Gelmon K, Nielsen TO, Kennecke $\mathrm{H}$. Breast cancer subtypes and the risk of local and regional relapse. J Clin Oncol. 2010;28(10):1684-1691.

25. Carey LA, Dees E, Sawyer L, et al. The triple negative paradox: primary tumor chemosensitivity of breast cancer subtypes. Clin Cancer Res. 2007;13(8):2329-2334.

26. Blows FM, Driver KE, Schmidt MK, et al. Subtyping of breast cancer by immunohistochemistry to investigate a relationship between subtype and short and long term survival: a collaborative analysis of data for 10,159 cases from 12 studies. PLoS Med. 2010;7(5): e1000279.

27. Partridge AH, Gelber S, Piccart-Gebhart MJ, et al. Effect of age on breast cancer outcomes in women with human epidermal growth factor receptor 2-positive breast cancer: results from a herceptin adjuvant trial. J Clin Oncol. 2013;31(21):2692-2698.

28. Arvold ND, Taghian AG, Niemierko A, et al. Age, breast cancer subtype approximation, and local recurrence after breast-conserving therapy. J Clin Oncol. 2011;29(29):3885-3891.

29. Cheng SH-C, Yu B-L, Horng C-F, et al. Long-term survival and stage I breast cancer subtypes. J Cancer Res Pract. 2016;3(1): $1-8$. 
30. Sørlie T, Perou CM, Tibshirani R, et al. Gene expression patterns of breast carcinomas distinguish tumor subclasses with clinical implications. Proc Natl Acad Sci U S A. 2001;98(19):10869-10874.

31. Hoteit M, Al-Shaar L, Yazbeck C, et al. Hypovitaminosis D in a sunny country: time trends, predictors, and implications for practice guidelines. Metabolism. 2014;63(7):968-978.

32. Arabi A, Mahfoud Z, Zahed L, El-Onsi L, El-Hajj Fuleihan G. Effect of age, gender and calciotropic hormones on the relationship between vitamin D receptor gene polymorphisms and bone mineral density. Eur J Clin Nutr. 2010;64(4):383-391.
33. Nottegar A, Veronese N, Senthil M, et al. Extra-nodal extension of sentinel lymph node metastasis is a marker of poor prognosis in breast cancer patients: a systematic review and an exploratory meta-analysis. Eur J Surg Oncol. 2016;42(7):919-925.

34. El Chediak A, Alameddine R, Hakim A, et al. Age less than 40 years is an independent predictor of worse prognosis among Lebanese nonmetastatic breast cancer patients: analysis from a prospective cohort. Abstract presented at: 4th Annual Beirut Breast Cancer Conference: Advances in Breast Cancer Management and Updates; February 11-13, 2016; Beirut, Lebanon.

\section{Publish your work in this journal}

Breast Cancer - Targets and Therapy is an international, peerreviewed open access journal focusing on breast cancer research, identification of therapeutic targets and the optimal use of preventative and integrated treatment interventions to achieve improved outcomes, enhanced survival and quality of life for the cancer patient.
The manuscript management system is completely online and includes a very quick and fair peer-review system, which is all easy to use. Visit http://www.dovepress.com/testimonials.php to read real quotes from published authors.

Submit your manuscript here: https://www.dovepress.com/breast-cancer---targets-and-therapy-journal 